\title{
Editorial
}

\section{EL (QUE) HACER DE LAS “CIENCIAS” SOCIALES, EL DESARROLLO Y LAS POLITICAS PÚBLICAS EN COLOMBIA}

\author{
Javier Francisco Franco Mongua (docente UMNG)" \\ Juan Carlos Villalba Cuéllar (editor) \\ Andrés González Serrano (coeditor)
}

DOI: http://dx.doi.org/10.18359/dere.930

Desde el Renacimiento y Descartes, pasando por Galileo, Copérnico, Kepler, Newton, Leibniz, Kant y Pascal, hasta los autores del siglo XX como Wittgenstein, Popper, Kuhn, Feyerabend, Elster, los filósofos hermenéuticos, los teóricos de las ciencias y un número incalculable de expertos; el debate sobre la forma en que llegamos a conocer, la potencialidad del conocimiento, su naturaleza y la manera en que podemos delimitar "la ciencia", la posibilidad de distinguir este tipo de saber con otros y si entre ellos pueden o no existir "diálogos" aún no se cierra sino que se profundiza.

Por otro lado, hay una discusión -al parecer también inacabada- en torno a las causas del "desarrollo", cuyo concepto sigue en controversia. Son varios economistas y algunos Premios Nobel de Ciencias Económicas como los neoclásicos, Friedman, Von Mises, Von Hayek, Kuznets, Schultz, Lewis, Coase, North y Sen, además de profesionales de sociología, antropología e historia quienes se preguntan sobre el bienestar, el desarrollo y el progreso.

El Estado colombiano en su Constitución garantiza la libertad de enseñanza y aprendizaje (artículo 27), permite la libertad de oficio (artículo 26) y busca regular la vida cultural de la nación. Además organiza un sistema de "ciencia", tecnología e innovación, con un destacado papel de un departamento administrativo, como lo es Colciencias; regulado mediante la ley 1289/2009. Esta entidad diseña las políticas públicas desde el
Estado, por medio de las cuales fija metas, prioriza recursos y regula la investigación científica en el país, entre otras actividades.

La investigación científica en Colombia es una de las funciones de las universidades -a las cuales se les reconoce su "autonomía" (Constitución Política, art. 69) - y el Estado promueve las condiciones de su ejercicio; al tiempo que se entiende el acceso a la educación científica como un elemento de la cultura, y expresamente se propone:

La cultura en sus diversas manifestaciones es fundamento de la nacionalidad. El Estado reconoce la igualdad y dignidad de todas las que conviven en el país. El Estado promoverá la investigación, la ciencia, el desarrollo y la difusión de los valores culturales de la nación (Constitución Política, art. 70; énfasis fuera de texto).

Con lo anterior esta editorial procura advertir sobre un gran debate que se da en la actualidad al interior del "campo científico y académico" de Colombia, a partir de las políticas públicas del Estado, en particular las que se reflejan en determinaciones puntuales de Colciencias en temas como convocatorias para financiación de proyectos, reconocimiento y clasificación de investigadores, grupos de investigación, publicaciones y otros aspectos que no han tenido pacífica acogida y que han marcado los últimos años, y en especial los últimos meses de polémica nacional en estas áreas.

Javier.franco@ugc.edu.co

Bogotá, D.C., Colombia - Volumen XVIII - Número 36 - Julio - Diciembre 2015 - ISSN 0121-182X 
Como es un debate inacabado y en avance, nos remitiremos a fuentes de prensa en torno a las cuales intentaremos describir la situación, para al final fijar sino una posición, por lo menos unas ideas alrededor de estas situaciones, que inquietan a los profesionales y a los miembros de la comunidad académica relacionados con las ciencias sociales.

\section{La investigación en las ciencias sociales}

En las últimas convocatorias de Colciencias para reconocer y clasificar investigadores y grupos de investigación se tiene en cuenta variables que se asocian con el nivel de formación de aquellos, la cantidad de publicaciones en revistas indexadas nacionales e internacionales, el "impacto" de los productos y proyectos realizados y la visibilidad (citación) de estos.

Sin embargo las convocatorias, en especial la número 693 de 2014, tiene como consecuencia el descontento de investigadores, sobre todo de las áreas de sociales y humanidades (Observatorio de la Universidad Colombiana, 2015), al punto que la resolución 841/2014, mediante la cual se adoptó la convocatoria, ha sido demandada ante las autoridades jurisdiccionales (El Espectador, 10 de mayo de 2015).

Para el Estado y sus entes responsables de ciencia y tecnología había problemas en el sentido de que no existía riguroso control sobre la verificación de los frutos de investigación y su calidad, y podría darse el caso de que el mismo documento fuese presentado por más de una institución de educación superior (IES). Esto surge en gran medida por la "comercialización" del saber y de sus productos: muchos investigadores venden sus obras a las IES a través de proyectos que no tienen necesariamente arraigo con las mismas o simplemente son "compradas" para que las IES puedan mostrar resultados investigativos al Estado y la sociedad.

La solución estatal ante estas prácticas fue establecer una presunción de mala fe sobre los investigadores colombianos y sus productos de investigación. Aunque lo curioso es que el mismo organismo que creó y organizó el sistema de investigación y de medición de los resultados de investigación colombianos, hoy en día los pone en entredicho.

Las universidades y especialmente los investigadores, responden que las nuevas convocatorias no tienen en cuenta las características particulares de las disciplinas ni la realidad de la academia y de las publicaciones universitarias: no se toma el mismo tiempo escribir un artículo en ciencias naturales -en las que los experimentos son la base de la investigación-que en ciencias sociales -en las que la mayoría de investigaciones requiere otro tipo de métodos que las pueden hacer más complejas para obtener resultados-.

Así mismo se esgrimen las deficiencias de la plataforma de Colciencias (en la cual deben registrarse los productos) y el excesivo tiempo que gastan los profesores tratando de demostrar, "certificando sus productos", que no están incurriendo en fraudes, ya que sobre estos pesa una presunción de mala fe (Dinero, 14 de mayo de 2015).

El tema de fondo es la naturaleza científica o no de ciertas disciplinas, con su estatuto epistemológico: ¿para Colciencias y el Estado colombiano las ciencias sociales y las humanidades tienen o no el carácter de ciencia? ¿Las convocatorias pueden llegar a discriminar a las ciencias sociales, pues se les mide de la misma manera que a las ciencias naturales, a pesar de que la forma en que producen conocimiento es diferente? Otro punto a tener en cuenta es el impacto: en ciencias sociales y humanidades no existen indicadores como las patentes o los modelos de utilidad. El modo en que contribuyen al desarrollo es distinto a las ciencias naturales.

Allí viene la otra pregunta: chay posibilidades de innovación y contribución al desarrollo más allá de las ciencias naturales y la ingeniería? ¿Es viable aportar desde disciplinas como la economía, el derecho, la sociología, la historia y la antropología al "progreso" de Colombia? 
Un Estado que dice ir en búsqueda del bienestar y que afirma prepararse para el posconflicto (sea lo que ese Estado entienda por tal), podría valorar el papel de los científicos sociales para contribuir a mejorar la vida y la convivencia de los asociados.

Por otro lado, tal vez no haya la cifra adecuada de revistas para el número de investigadores que hay en Colombia, especialmente en ciencias sociales. Y por otro, la existencia de ciertos "índices" de publicaciones, en ocasiones dependen más de pagar membresías que de la pura calidad académica. La mayoría de ellos no son pagos, pero por coincidencia algunos de los que precisó Colciencias como requisito para acceder a ciertas categorías de indexación en Publindex, las más altas, sí lo son.

No es claro entonces si para publicar en revistas indexadas, baste la excelencia del producto investigativo, o la chequera de la universidad de la que proviene el producto o del patrocinador del mismo. El Premio Nobel de Medicina 2013, Randy Schekman, en un interesante artículo sobre este tipo de revistas abrió un debate al respecto (Schekman, 2013). El profesor David Ernesto Llinás presentó la demanda citada sobre los índices y advierte que:

Colciencias parte del inamovible según el cual las publicaciones que aparezcan indexadas en las bases de datos de algunas multinacionales de la información son "más científicas" que aquellas que no se encuentran en esos listados, y así se refleja en los puntajes que asigna la convocatoria. Esas bases de datos son, por mencionar algunas, la 'Science Citation Index (SCI)', la 'Social Science Citation Index (SSCI)', y la 'Arts and Humanities Citation Index' para revistas especializadas, y la 'Book Citation Index' para libros científicos, todas ellas propiedad de Thomson Reuters. Esta lógica es incorrecta, y conlleva que las publicaciones en inglés sean consideradas "más científicas", pues son muy pocos los productos académicos escritos en otros idiomas, incluido el español, que se encuentran referenciados en esas bases de datos.

Inclusive, en el mundo de las ciencias sociales y jurídicas hay editoriales europeas muy importantes que no aparecen dentro de las bases de datos de Thomson Reuters, y por esa razón autores como Luigi Ferrajoli, Gerardo Pisarello, Gustavo Zagrebelsky, Jürgen Habermas y Robert Alexy, en el terreno de las ciencias jurídicas y sociales, no serían considerados como científicos de calidad por Colciencias. Algo parecido pasa con los autores nacionales, pues casi ningún jurista es científico al no haber sido publicadas sus obras en editoriales "científicas" según los parámetros establecidos por Colciencias. Todo esto configura una violación del derecho a la igualdad de estos investigadores.

Adicionalmente, en la demanda se plantea que la convocatoria 693 de 2014 vulnera normas legales relativas al principio de la buena fe, como los artículos $2^{\circ}$ a $9^{\circ} \mathrm{del}$ decreto ley 019 de 2012; algunas normas legales relativas a la manera en que se pueden transferir funciones de los organismos públicos a otras entidades, públicas o privadas, como las señaladas en los artículos 9, 10, 14, 110 y 111 de la ley 489 de 1998; y las normas sobre autonomía universitaria establecidas principalmente en la ley 30 de 1992 (El Espectador, 10 de mayo de 2015).

Se olvidan además las especificidades de cada campo disciplinar y la verdadera finalidad de las publicaciones científicas: difundir conocimiento. Para nuestro caso en materia jurídica, los artículos de los docentes investigadores tienen en un alto porcentaje de los casos un interés netamente interno, que no obstante aportan mucho a las discusiones sociales que se necesitan sostener en el país.

Pongamos un ejemplo, un artículo se refiere a la protección de los derechos de las comunidades indígenas del departamento del Cauca, pero para Colciencias este escrito será menos valioso 
si no es publicado en una revista que esté en una base Scopus -donde casi siempre los textos deben estar en idioma inglés-. ¿Qué tanto interés tiene el tema para el contexto anglosajón, que ni siquiera pertenece a la misma familia jurídica? ¿Qué tantos lectores colombianos interesados en la materia, que de por sí son pocos, podrán leer el documento en inglés? ¿Qué función cumplió dicho artículo publicado en el International Law Review de una universidad norteamericana, si acaso a ellos les interesa publicarlo?

Debemos pensar si realmente estamos haciendo academia e investigación para la sociedad y los problemas colombianos, o si lo único que importa es incluirnos per se en bases de indexación, para poder aparecer en rankings de mediciones internacionales con un cuestionado alcance global sacrificando lo que en verdad es relevante. Es triste pensar que una academia hasta ahora en estado embrionario como la colombiana, se autosometa y genere dependencia de criterios de medición que no tienen validez universal, tal y como lo sugiere el profesor Marquardt (2015).

No hemos visto la primera publicación anglosajona queriendo entrar a Publindex o a SciELO Colombia, por razones que para ellos son obvias. Fijémonos que en países como Francia, España o Alemania, o para no ir tan lejos en la Argentina, las publicaciones jurídicas no son esclavas por mandato estatal de parámetros de medición externos para evaluar la validez y la calidad de sus escritos. ¿Podríamos cuestionar la calidad de sus publicaciones? El modelo creado entonces se vuelve excluyente, ya que toda revista que no pertenezca a dichas bases es menospreciada por el sistema estatal de medición.

\section{Lo que aporta Colciencias}

No queda claro qué aporta Colciencias: las universidades hacen investigaciones en gran medida financiadas con recursos propios -el Estado colombiano últimamente ha mejorado la contribución a las investigaciones, sobre todo con recursos de regalías, pero haciendo énfasis en investigaciones aplicadas, ciencias naturales e ingeniería-. ¿Y con qué contribuye Colciencias? Muchos pueden responder que su papel de fomento no implica financiación. Lo cual puede -en gracia de discusión- ser cierto. Pero si son las propias IES las que utilizan sus recursos para pagar por la investigación, ¿̇por qué no pueden definir ellas sus prioridades y esperar de manera legítima que las mismas sean valoradas por Colciencias?

En Colombia la autonomía universitaria es fuertemente criticada por abusos que han terminado en escándalos y tragedias de IES postradas y cerradas -que son de público conocimientopero también es un valor de la modernidad en este continente, y esa autonomía puede verse vulnerada por la imposición de modelos de medición como los adoptados aquí. Siempre queda la alternativa de no someterse, y ello es un interesante indicador del punto al que ha llegado el debate (El Espectador, febrero de 2015).

La reciente medición - esa que ha sido tan criticada- de grupos muestra aspectos preocupantes como la falta de investigación en muchas IES, incluso en algunas "acreditadas como de alta calidad" por el Estado colombiano (Observatorio de la Universidad Colombiana, 2015). En ese caso, la pregunta sería si para organismos como el Consejo Nacional de Acreditación no es una prioridad la investigación científica o si se valoran otras variables con mayor peso que ella.

El número de grupos de investigación reconocidos y categorizados se redujo de forma importante y esto nos lleva a la duda ya mencionada: el Estado colombiano dice tener entre sus fines el fomentar la educación y la investigación científica, pero pretende que sean las universidades -en gran medida privadas- las que la financien y luego impone modelos de medición que no son consensuados y que reciben reproches de los actores y sujetos de medición. La capacidad del Estado para cumplir con sus funciones también queda en entredicho en programas como los de "retorno de cerebros fugados" y los presuntos incumplimientos de promesas hechas (El Espectador, 21 de enero de 2015, 30 de marzo de 2015). 
Si la ciencia en Colombia tiene las dificultades que el mismo Estado reconoce, a pesar de haber sido por décadas el organismo rector de la actividad en el país, ¿no es hora de cambiar el patrón de medición, repensar esa entidad y crear un nuevo modelo de fomento a la investigación científica?

Para instituciones públicas del orden nacional quedan interrogantes que no deben ser solucionados por los miembros de esta revista, sino por las autoridades académicas y de investigación:

¿Si más de la mitad de los programas de estas universidades no corresponden a ciencias naturales o ingeniería, no debería tenerse en cuenta las particularidades de la investigación en las ciencias sociales, económicas, el derecho y las humanidades al momento de diseñar las convocatorias internas? Si bien se trata de universidades públicas, ¿̇para qué sirve el concepto de autonomía universitaria frente al tema de la investigación y en particular considerando la pregunta anterior? Si se pretende publicar en índices internacionales que parecen "clubes de onerosa membresía", ¿́cuánto dinero público están dispuestas a invertir en ser parte de esas asociaciones de costosos amigos?

Todas estas reflexiones tan solo se unen a una discusión que debe necesariamente darse al interior de la sociedad y de la academia colombiana, si es que esta última existe, en aras de que los actores del sistema educativo y el Estado acuerden unas políticas de la evaluación de la investigación y de la producción científica que correspondan realmente a las necesidades nacionales y al verdadero fomento de la investigación. Es menester así mismo que el Estado valore la investigación en ciencias sociales, pero esto pasa por una verdadera comprensión de sus métodos, de sus objetos de estudio y de las especificidades de los resultados de la investigación en este tipo de ciencias. 